\title{
Grana - Educação financeira para crianças de escolas rurais através de um jogo para dispositivos móveis.
}

\author{
Carlos H. L. Cavalcante ${ }^{1}$, Maria L. A. Pereira ${ }^{2}$, Claudiane G. Ferreira ${ }^{2}$, Francisco \\ A. G. Santos ${ }^{2}$, Ana A. C. Costa ${ }^{2}$, Rafael Lopes Costa ${ }^{2}$, Bruno Correia da Silva ${ }^{1}$, \\ Fernanda Felipe Leal ${ }^{3}$
}

\author{
${ }^{1}$ Instituto Federal de Ciência e Tecnologia do Estado do Ceará (IFCE) \\ Av. Parque Central, 1315 - Distrito Industrial I, 61939-140 - Maracanaú - CE - Brasil \\ ${ }^{2}$ Instituto Federal de Ciência e Tecnologia do Estado do Ceará (IFCE) \\ Rodovia BR 020, Km 303, s/n - Jubaia, 62700-000 - Canindé - CE - Brasil \\ ${ }^{3}$ Instituto Federal de Ciência e Tecnologia do Estado do Ceará (IFCE) - Campus Aracati \\ Rodovia CE-040, Km 137,1 s/n, 62800-000 - Aracati - CE - Brasil

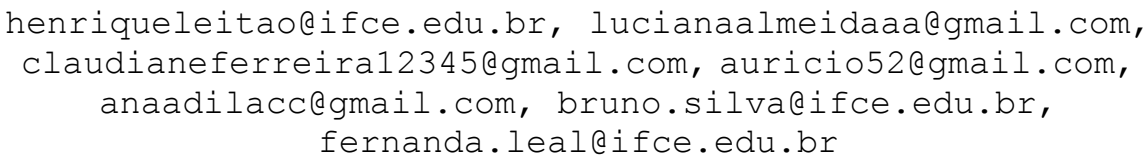

\begin{abstract}
This article introduces the development of a game for mobile devices that allows students from rural areas to learn financial education concepts. Its creation was based on gamification principles and user experience (UX). The game has levels with questions about everyday situations in sertão, a semi-arid region inland, located in the northeast part of Brazil. There is also a reward system where the coins can be used in the game store or saved. The application was tested with 15 students, obtaining a high degree of acceptance and playability. In external studies, the software was analyzed, evaluated and classified as a learning object. Currently, it can be downloaded from the Google Play Store.
\end{abstract}

Resumo. Este artigo apresenta o desenvolvimento de um jogo para dispositivos móveis que transmite conceitos de educação financeira para alunos de escolas rurais. Sua criação foi norteada pelos princípios de gamificação e user experience $(U X)$. O jogo possui níveis com perguntas sobre situações do cotidiano do sertão nordestino e um sistema de recompensa através de moedas que podem ser usadas na loja do jogo ou guardadas. O aplicativo foi testado com 15 alunos, obtendo um alto grau de aceitação e jogabilidade. Em estudos externos, o software foi analisado, avaliado e enquadrado como objeto de aprendizagem. Atualmente, pode ser baixado na play store da Google.

\section{Introdução}

Em fevereiro de 2021, foi divulgada uma pesquisa realizada pela Confederação Nacional do Comércio de Bens, Serviços e Turismo (CNC) indicando que o índice de endividamento das famílias brasileiras chegou a 66,5\% em janeiro de 2021, deste percentual 10,9\% não terão condições de pagar suas dívidas [CNC 2021].

Situações de endividamento e decisões erradas no contexto financeiro poderiam ser evitadas se o conhecimento sobre Educação Financeira fosse abordado fortemente 
desde a infância. Assim, a possibilidade de formação de adultos mais conscientes no uso do dinheiro e na tomada de decisões financeiras aumenta. Esse problema da falta de conhecimento sobre finanças está presente nas grandes cidades e se intensifica nas zonas rurais, onde o acesso ao ensino de qualidade é mais precário.

$\mathrm{O}$ acesso à internet e ao celular vêm crescendo e sendo democratizado no Brasil nos últimos anos, contudo as áreas rurais do norte e nordeste do país apresentam números piores quando comparados à média nacional do uso desses recursos [CGI.br 2019]. O uso conjunto dessas duas tecnologias permite obter informação em qualquer lugar e possibilita o desenvolvimento de objetos de aprendizagem (OA) que facilitam a transmissão do conhecimento. Os OA podem ser definidos como um recurso digital que tem a finalidade de apoiar o aluno no processo de aprendizagem. Eles podem ser de diversos tipos, tais como: textos, vídeos, imagens, aplicações, páginas Web, aplicativos e jogos [Carneiro e Silveira 2014].

A busca pela facilitação do acesso ao conhecimento e pela atenção das crianças, jovens e adultos é um elemento que contribui para o crescimento da construção de ferramentas como aplicativos e jogos no contexto educacional para dispositivos móveis [Barbosa e Pio 2020]. Essa área de jogos educativos vem ganhando relevância no Brasil, visto o número de jogos criados entre os anos de 2016 a 2017, em que aproximadamente 1700 jogos produzidos no país, a metade $(50,87 \%)$ são do tipo educacionais digitais [Brasil 2018].

Nesse contexto, o objetivo deste trabalho foi desenvolver, baseado nos princípios da gamificação, um jogo para dispositivos móveis que pudesse transmitir conceitos de educação financeira de uma forma lúdica e contextualizada com a temática rural nordestina.

A estrutura do trabalho está organizada da seguinte forma: na seção 2, faz-se uma introdução sobre educação financeira, gamificação e jogos na educação e pesquisas relacionadas; na seção 3, apresenta-se a metodologia e o processo de desenvolvimento do aplicativo; na seção 4, aborda-se a história e o desenvolvimento do Grana; na seção 5, apresenta-se os resultados da pesquisa e do desenvolvimento do jogo; por fim, na seção 6 , apresenta-se as considerações finais e trabalhos futuros deste projeto.

\section{Fundamentação Teórica}

\subsection{Educação financeira}

No mundo contemporâneo, todos devem conhecer e compreender os métodos e conceitos que norteiam o sistema financeiro de seu país, saber quais atitudes tomar frente a cada situação, sempre priorizando as decisões que podem ser mais assertivas. A educação financeira é o processo de aprendizagem ligado às informações pessoais sobre finanças, em que a sociedade pode criar uma consciência e fazer um uso racional do dinheiro. Ela está prevista inclusive no currículo escolar brasileiro, porém a mesma não está contida nos Parâmetros Curriculares Nacionais, tampouco nas Diretrizes Curriculares Nacionais (DCN) [Cordeiro et al 2018].

\subsection{Gamificação}

A gamificação se refere ao uso de mecanismos e dinâmicas de jogos para a resolução de problemas e para a motivação e o engajamento de um grupo alvo específico para a 
realização de uma atividade ou tarefa [Vianna et al 2013]. Elementos como os desafios, os objetivos a serem alcançados e as regras a serem seguidas pelo usuário servem para definir o grau de dificuldade que o jogador enfrentará e para estimular a sua permanência e engajamento no jogo de forma voluntária e ativa.

Outro elemento importante é o sistema de feedback que permite ao jogador avaliar o seu progresso mesclado com um sistema de recompensas que, por sua vez, motivará o jogador a se esforçar para obter sucesso diante de seus objetivos [Borys 2013].

\subsection{Experiência do Usuário (User Experience - UX)}

Criado em 1990 pelo psicólogo cognitivo Donald Norman, o termo experiência do usuário (User Experience - UX) se preocupa em entregar ao consumidor experiências com base em um design responsivo, agradável, organizado e intuitivo NORMAN apud [Buley 2013]. Já o User Experience Design (UX Design) estuda como os elementos que o usuário utiliza em um sistema podem afetar seu comportamento e suas percepções [Unger e Chandler 2010].

O UX Design baseia-se em conceitos fundamentais, princípios e metodologias para sua implementação. Como conceitos, pode-se citar: usabilidade, acessibilidade, arquitetura de informação, desenho centrado no usuário, interação, estilos de interação, acessibilidade, necessidade e estratégias de busca de informação e relação custobenefício. Quanto aos princípios, podem ser citados princípios de desenho, classificação, cor, eficiência, erro humano, estética, fotografías, Gestalt, ícones, inteligência coletiva, hierarquia visual, legibilidade e inteligibilidade, Lei de Fitts, mapa natural, ordenação, relevância, taxonomías, tomada de decisões, visibilidade e retroalimentação. Em relação a metodologias, as propostas de Garrett (2011) e Unger e Chandler (2010) são exemplos de propostas de processos para criação de aplicativos digitais através do uso do $U X$ Desing.

\subsection{Jogos na educação}

Para Freitas e Maharg (2011), jogar é considerado uma importante atividade para o desenvolvimento psicológico, social e cognitivo do aluno. Os jogos educacionais são importantes para que as crianças possam aprender conteúdos curriculares por meio de experiências e situações que promovam a inserção de habilidades motoras, cognitivas e sociais nas crianças, o que pode enriquecer o seu desenvolvimento intelectual [Campos, Bortoloto e Felicio, 2002].

Diversos jogos educacionais estão disponíveis na internet e nas lojas virtuais de dispositivos móveis, mas apenas alguns abordam a temática da educação financeira. $\mathrm{O}$ "Finance Game" de Junior et al. (2015) simula a vida de um trabalhador que precisa administrar uma casa e uma lanchonete por meio da prática de atividades financeiras, tais como pagar contas e comprar produtos. Nesse jogo, a qualidade de vida é alterada de acordo com as decisões do jogador. Kliszcz et al. (2016, p.30) propõe o jogo chamado "Vamo\$ às Compras" que ensina ludicamente os conceitos específicos de matemática básica e introduz os fundamentos da educação financeira para crianças de 6 a 10 anos.

$\mathrm{Na}$ Google Play Store, por exemplo, é possível encontrar vários jogos educacionais para dispositivos Android que visam ensinar educação financeira para 
crianças, como o EDUCA BRB ${ }^{1}$, KIDS EMPREENDU² e POUPADIN³.

\subsection{Motor do jogo (Game Engine)}

Um Motor de Jogo (Game Engine) pode ser definido como um conjunto de módulos específicos que oferecem ferramentas para facilitar a criação de jogos. Através desses módulos, fica mais fácil a manipulação gráfica, como: a renderização de imagens em 2D ou 3D, as colisões físicas entre os objetos e gerenciamento da taxa de quadros por segundos (Frames per Seconds - FPS) para garantir a fluidez da animação nos jogos. Geralmente esses motores são criados tendo como base uma linguagem de programação compilada com um alto desempenho, como por exemplo C e C++ [Enger 2013]. Existem diversos games engines, a citar Unity, Godot, Phaser, GameMaker, Construct 2, RPG Maker, CryEngine, Frostbite, Luminous Engine, Fox Engine, Panta Rhei e REDengine 3. Neste trabalho, foi escolhido o Godot.

\section{Materiais e Métodos}

\subsection{Metodologia e etapas do projeto}

O projeto foi desenvolvido em quatro etapas, entre os anos de 2018 e 2021, e adotou a metodologia de pesquisa-ação, cujo processo aponta soluções para os problemas que se deseja resolver [Nunes e Infante 1996, p.224]. O estudo teve uma abordagem quantitativa, utilizando questionários como fonte de dados.

Inicialmente, foram realizadas uma análise de viabilidade e um levantamento dos requisitos para a criação do jogo para crianças na faixa etária de 08 a 12 anos de idade. Para isso, foram realizadas palestras com elementos rurais sobre gestão financeira em escolas de comunidades rurais do interior de Canindé no estado de Ceará. Foram realizadas reuniões utilizando a técnica de dinâmica em grupo brainstorm para coleta dos requisitos. Em seguida, os questionários pré-testados foram aplicados para a coleta de informações sobre o uso de celular, acesso à internet, profissão dos pais, jogos em celulares e conceitos de educação financeira. Todos os dados coletados foram analisados, condensados e serviram de insumos para a definição das funcionalidades e o tipo de jogo a ser desenvolvido.

A segunda etapa teve como objetivo a escolha da game engine para o desenvolvimento do jogo. Algumas games engines foram comparadas, uma vez que a equipe não tinha experiência no desenvolvimento desse tipo de software. Para tal análise, foram consideradas as interfaces e funcionalidades das plataformas Unity, Godot e Phaser. Para cada uma delas, foi desenvolvido um jogo que utiliza conceitos da física em relação a movimento e colisão, permitindo conhecer os detalhes e identificar os pontos fortes e fracos de cada uma das engines. Maiores detalhes do comparativo dessas engines e os motivos que levaram a escolha do Godot para o desenvolvimento do projeto encontram-se no estudo de Cavalcante e Pereira (2018).

Na terceira etapa, iniciou-se a programação do jogo, a criação da interface e das

\footnotetext{
${ }^{1}$ https://apps.apple.com/br/app/educa-brb-educa\%C3\%A7\%C3\%A3o-financeira/id1227087070

${ }^{2} \mathrm{https}: / / \mathrm{m}$.apkpure.com/br/kids-empreendu/com.dojoh.kidsempreendu

${ }^{3} \mathrm{http}: / /$ poupadin.sinextra.com
} 
perguntas e respostas. Na última etapa, foram realizados testes com 15 alunos, em uma faixa etária de 8 a 11 anos, provenientes de 3 escolas rurais localizadas em duas cidades diferentes do interior do estado do Ceará. Para a realização dos testes, foram disponibilizados tablets e celulares para as crianças e, em seguida, aplicados questionários pré-testados com o objetivo de identificar o nível de conhecimento financeiro dos alunos antes e após a utilização do jogo. Os questionários tiveram como base o teste de educação financeira para crianças de Reinaldo Domingo ${ }^{4}$, sendo adotado o mesmo sistema de pontuação proposto pelo autor na classificação das respostas. Os instrumentos de coleta de dados estão disponíveis para visualização na internet ${ }^{5}$.

\section{Resultados}

\subsection{Análise de viabilidade e levantamento dos requisitos}

A primeira etapa para a elaboração deste projeto consistiu na realização de um estudo de viabilidade e levantamento de requisitos. Nessa etapa, foi aplicado um questionário a 22 estudantes da zona rural de Canindé-CE. Constatou-se que $56 \%$ das crianças preferiam jogos offline pela portabilidade de utilizá-lo em qualquer local, sem a necessidade de ter conexão com a internet e $84 \%$, preferiam jogar no celular. Com base nesses dados e na pesquisa TIC Domicílios 2019 [CGI.br 2019], foi definido que o jogo a ser desenvolvido deveria ser para dispositivos móveis e não necessitar de conexão com a internet para seu uso. Como resultado do brainstorm com as crianças, foi possível identificar alguns requisitos não funcionais, como: a jogabilidade simples, possuir desafios, fases com missões a serem cumpridas, recompensas com a possibilidade de realizar compras, ter um cenário colorido baseado nos elementos naturais da região (ex: animais, plantas e etc.) e música animada.

Tabela 1. Valor das premiações em cada nível e a quantidade total de perguntas.

\begin{tabular}{|c|c|c|}
\hline NÍVEL & PERGUNTAS & RECOMPENSA TOTAL \\
\hline 1 & 2 & 400 moedas \\
\hline 2 & 3 & 600 moedas \\
\hline 3 & 5 & 1.000 moedas \\
\hline 4 & 8 & 1.600 moedas \\
\hline 5 & 13 & 2.600 moedas \\
\hline
\end{tabular}

Após essa etapa inicial, definiu-se que o jogo seria um Quiz, que consistem em um conjunto de perguntas para avaliar os conhecimentos do aluno. Definiu-se que o software seria denominado Grana, teria 5 níveis com diferentes quantidades de perguntas. Como mecanismo de recompensa, definiu-se um sistema de moedas que possibilita ao jogador realizar decisões de compra ao passar por cada fase. Os níveis, quantidade de perguntas e o valor da recompensa são apresentados na Tabela 1. A escolha da quantidade

\footnotetext{
${ }^{4}$ https://www.infomoney.com.br/colunistas/financas-em-casa/faca-o-teste-e-descubra-qual-a-sua-situacaofinanceira/

${ }^{5}$ Testes - Instrumentos de Coleta de Dados.pdf
} 
de questões considerou a sequência de Fibonacci $(F n=F n-1+F n-2)$ que pode ser percebida na natureza a citar a ocorrência em folhas de árvores, pétalas de rosas, caracóis entre outros elementos naturais [Mello 2018].

Há diversos princípios de gamificação no jogo. Inicialmente, através dos níveis com perguntas, aplica-se o desafio profundo. Em seguida, o sistema de recompensas com moedas e a possibilidade de compra de produtos na loja estimulam o engajamento do aluno, fazendo-o com que se esforce para progredir no jogo. A visualização do acerto ou erro da resposta fornece um feedback instantâneo para a criança tentar novamente até o acerto da questão [Borys 2013].
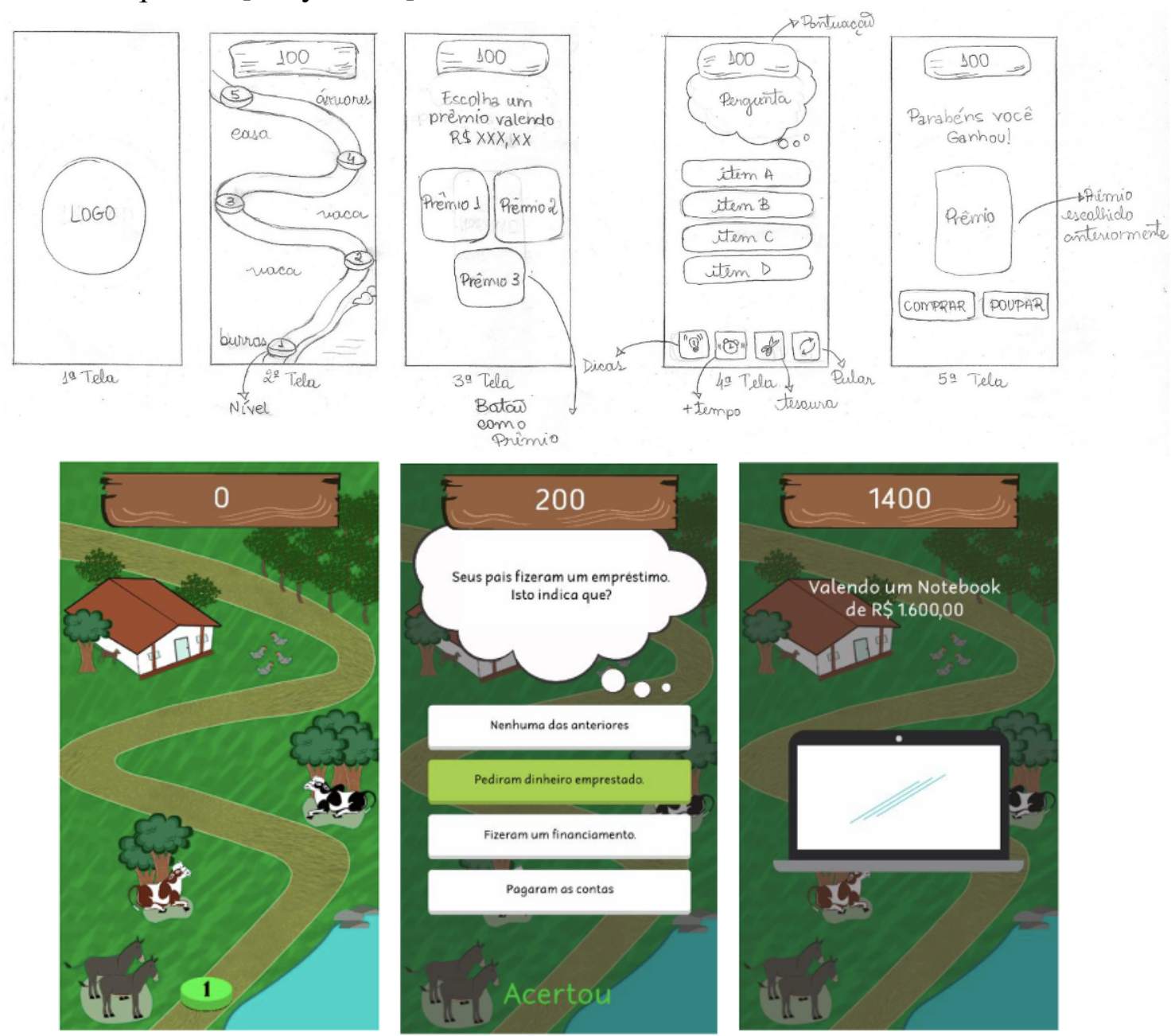

Figura 1 - Protótipos de baixa e de alta fidelidade.

\subsection{Desenvolvimento do jogo}

O desenvolvimento do Grana foi realizado entre os anos de 2018 e 2020 . As atividades foram divididas em sprints de 15 dias, com reuniões de acompanhamento diários e quinzenais. Como ferramenta de gestão de atividades foi utilizado a ferramenta Trello. As atividades se dividiram em três frentes: criação das perguntas, criação do cenário e programação do jogo.

Para a criação das perguntas, priorizou-se a criar situações que permitissem o contato do jogador com conceitos de educação financeira por meio da utilização de elementos e situações presentes no cotidiano do sertão nordestino. Foram abordados 
assuntos como: economia, lucro, controle, investimento e situações. Todas as perguntas podem estar disponíveis na internet para visualização ${ }^{6}$.

Essa preocupação com a regionalidade norteou a criação do design. Tendo em vista o objetivo do trabalho, foram criados alguns protótipos que serviram de base para a versão final do cenário do jogo, em que definiu-se diversas telas, como: Início, Principal, Loja, Sobre, Apresentação, Personagem, Premiação do Nível, Níveis, Perguntas e Premiação. A Figura 1 apresenta a evolução do processo de criação da interface e a Figura 2 apresenta o resultado final do processo de criação das telas.

A tela de Início (Figura 2-a) apresenta uma animação com a logo do aplicativo. A tela Principal (Figura 2-b) contém as opções de iniciar um "Novo Jogo", "Loja" e "Sobre". Observa-se que elementos regionais, tais como o mandacaru, estão presentes no cenário. Na tela Loja (Figura 2-e), é possível comprar prêmios de acordo com a quantidade de moedas que o jogador possui. Estão disponíveis cinco prêmios fictícios que só possuem valor no jogo, a citar: um celular, um videogame, uma televisão, um notebook e uma viagem. A qualquer momento, o jogador pode clicar no botão "Fechar", localizado no topo direito, e retornar para tela anterior. A tela Sobre (Figura 2-f) possui informações acerca do jogo e da equipe que o desenvolveu.

Ao clicar em "Novo Jogo", na tela Principal, a tela de Apresentação (Figura 2-c) é exibida dando as boas-vindas. Nessa tela, o jogador pode ler todas as instruções do jogo ou pular para a próxima tela para definir o avatar do seu personagem. Na tela do Personagem (Figura 2-d), é possível escolher o perfil do jogador, momento em que se cria um vínculo entre o jogador e o jogo, uma vez que aquele se sente representado pelo avatar escolhido, que está caracterizado com elementos regionais. Em seguida, é apresentada a tela de Níveis (Figura 2-g). Como está sendo iniciado um novo jogo, apenas o primeiro nível está desbloqueado. Nesta tela, encontram-se diversos elementos do habitat da criança rural, tais como: animais, capela e estrada de terra. Ao clicar na imagem do Nível I, é apresentada a tela da Premiação do Nível (Figura 2-h) que automaticamente redireciona para as perguntas.

Na tela da Perguntas (Figura 2-i e 2-j), inicia-se o Quiz de perguntas e respostas, parte mais complexa do jogo, visto que apresenta várias informações e atalhos para outras telas. No topo da tela, é possível ver a quantidade de moedas que o jogador já acumulou, o nível que está jogando, a quantidade de moedas que adquiriu no nível e o tempo restante para responder a pergunta. Na parte inferior da tela, é possível acessar as ajudas com dicas, tempo adicional, a opção de pular a pergunta e remover um item errado. Ao escolher um dos itens da resposta, o jogo mostra o acerto ou erro da resposta.

Ao responder todas as perguntas de um nível, o jogador é redirecionado para a tela de Premiação (Figura 2-j). É possível poupar ou comprar algo na loja do jogo com a premiação recebida. Se escolhida a opção de poupar, o jogador volta para a tela de níveis e o jogo continua; se não, o jogador é direcionado para a loja para escolha de produtos. Se o jogador não acertar a quantidade mínima de questões para desbloquear o próximo nível, ele será questionado para determinar se deseja responder as perguntas novamente. Caso o jogador já tenha passado de nível e feche o aplicativo, seu progresso permanece registrado e, quando retornar, aparecerá a opção "Continuar Jogo" na tela principal.

${ }^{6}$ Perguntas.pdf 


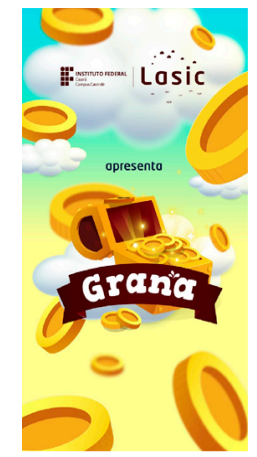

(a) Início

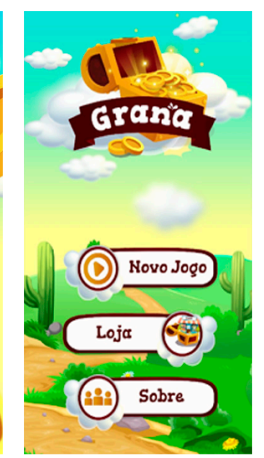

(b) Principal

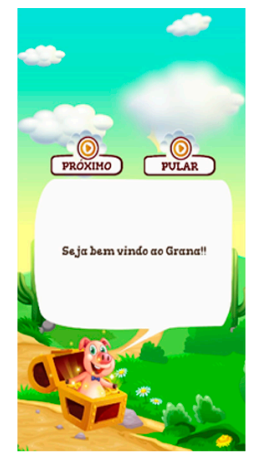

(c) Apr. do Jogo

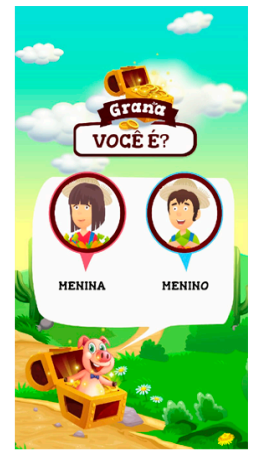

(d) Personagem

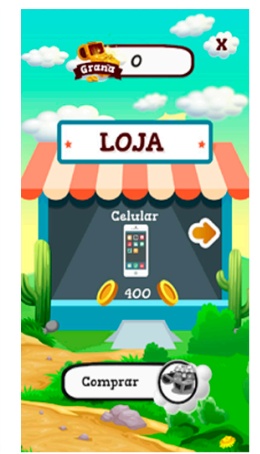

(e) Loja

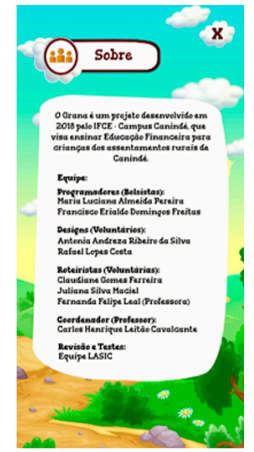

(f) Sobre

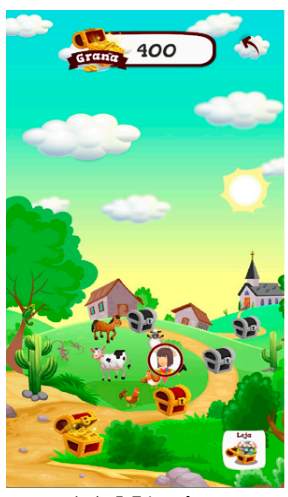

(g) Níveis

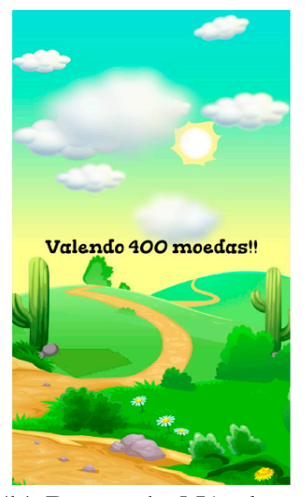

(h) Prem. do Nível

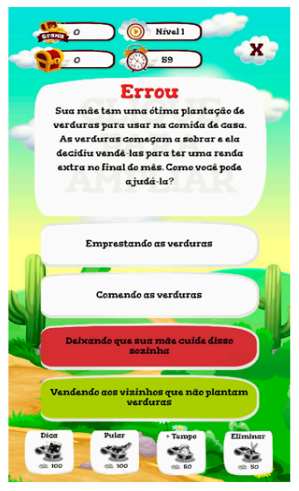

(i) Perguntas
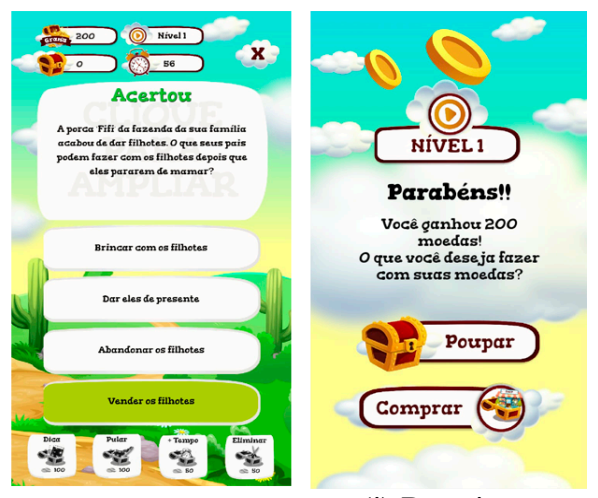

(j) Premiação

Figura 2 - Telas finais do jogo.

\subsection{Testes e Validações}

Após o desenvolvimento do jogo, este passou por uma fase de teste a fim de verificar se cumpria com o seu objetivo de repassar conhecimentos de educação financeira de forma lúdica em um contexto rural. A aplicação do teste para o usuário final é apresentada na Figura 3. Como resultado, observou-se que $47 \%$ dos alunos afirmaram estar satisfeitos e $53 \%$ muito satisfeitos com o jogo. Dentre os 15 alunos entrevistados, 53\% consideram o conteúdo do jogo importante e $67 \%$ tiveram facilidade em entender o jogo. Em relação aos conceitos de gestão financeira presentes nas perguntas e na decisão de compra, todos alunos afirmaram que aprenderam com o jogo e que o recomendariam; em termos de aparência, $86 \%$ afirmaram estar razoavelmente satisfeitos ou satisfeitos e que o cenário lembrava a localidade onde vivem, mas $14 \%$ se mostraram insatisfeitos. Durante o mês de novembro, a região do sertão onde o teste foi realizado passa um período estiagem em que a vegetação encontra-se seca e a paisagem possui um tom cinzento, algo diferente da aparência verde apresentada no jogo. Isso pode ter influenciado as respostas dos alunos.

Outro resultado interessante foi o fato de que $67 \%$ dos alunos apresentaram um "comportamento mais gastador" após a utilização do jogo. Analisando individualmente as respostas de cada aluno, percebeu-se que esse comportamento era mais presente em crianças com 8 ou 9 anos. Uma possível explicação seria devido a limitação financeira da criança, a ludicidade do jogo despertou um desejo de possuir bens de consumo, o que não fazem parte da sua realidade. Após a realização desses testes, os resultados e as informações obtidas serviram como fonte para melhorias e correções no jogo, permitindo 
o aprimoramento da versão inicial para uma mais estável a ser disponibilizada na loja Google Play.

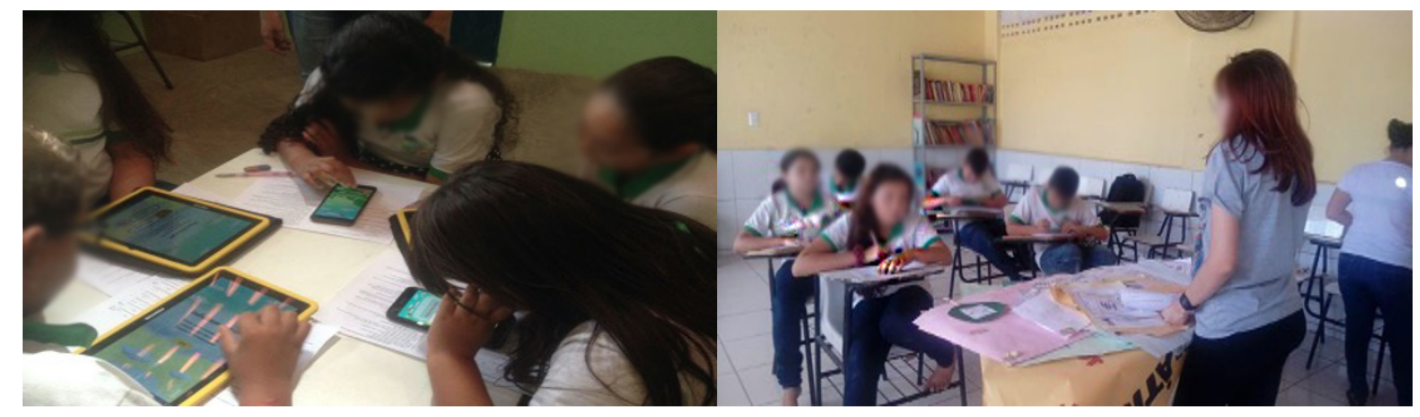

Figura 3 - Teste com alunos de escolas em localidades rurais.

Ramos e Lavor (2020) verificaram que o aplicativo apresenta características pedagógicas de autonomia, estimulando o usuário a ter iniciativa e a tomar decisões por meio da escolha entre comprar, buscar opções de ajuda para responder às perguntas e poupar suas moedas. Eles relatam que o jogo é interativo, possui elementos que possibilitam uma boa cognição e transmitem afetividade, visto que oferece conteúdos sobre educação financeira com carga cognitiva alocada na memória do usuário. Os pesquisadores destacam que as telas com diferentes cores atraem a atenção do jogador e as perguntas favorecem uma aprendizagem satisfatória. Apesar dos aspectos positivos, o jogo não aplica o quesito cooperação, o que seria uma limitação, mas isso pode ser superado pelo planejamento do professor ou tutor. Por fim, concluem sua análise e caracterizam o aplicativo como um objeto de aprendizagem e reforça que o jogo estimula a percepção do jogador para a importância de poupar, assegurando a realização de sonhos e ainda ter dinheiro para investimentos.

\section{Considerações finais e trabalhos futuros}

O Grana apresenta conceitos de gamificação e estimula no jogador o interesse pelas recompensas e pontuações por meio do acerto de perguntas. O jogo busca transmitir o conceito de consumo consciente para o jogador que precisar adotar esse comportamento para atingir os objetivos maiores dentro do aplicativo por meio do sistema de compra ou economia. O jogo foi idealizado para/e testado com crianças da região do sertão, obtendo uma boa avaliação quanto a sua usabilidade, seu cenário e sua linguagem. Além disso, o estudo foi analisado, testado, validado e recomendado por Ramos e Lavor (2020).

Utilizando uma temática regional do sertão nordestino, desenvolveu-se um jogo em que crianças trabalham os conceitos de educação financeira brincando. A criação de um conjunto de perguntas, que abordam situações do cotidiano rural dos alunos, aproximou a temática à realidade das crianças, tornando o aprendizado aplicável e lúdico. Dessa forma, é possível afirmar que o jogo cumpre com seu objetivo principal. Atualmente, o jogo encontra-se disponível para ser baixado na loja virtual da Google e já conta com mais 100 instalações em dispositivos Android, com nota de 4.8 de 5 na avaliação dos usuários.

Como proposta para trabalhos futuros, propõe-se o aumento da quantidade de níveis, a criação de novas perguntas e a adição de novas premiações. Sugere-se ainda a aplicação e adaptação do modelo do jogo para outras faixas etárias, como também a 
adaptação da versão atual para publicação em outras lojas além do Play Store, como: Apple Store, Amazon App Store, Apk Mirror e outras.

\section{Referências}

Barbosa, M. S. and Pio, J. L. S. (2020) "Jogos móveis como ferramenta na aprendizagem colaborativa: Uma revisão sistemática da literatura", In: Brazilian Journal of Development, pages 54735-54749.

Borys, M., and Laskowski, M. (2013). "Implementing Game Elements into Didactic Process: A Case Study", In: Research Papers in Economics, pages 819-824.

Buley, L. (2013) The User Experience Team of One: A Research and Design Survival Guide, Rosenfeld Media, New York.

Brasil. $2^{\circ}$ Censo da Indústria Brasileira de Jogos Digitais aponta crescimento de games no Brasil. Ministério da Cultura. 2018. 329p. Disponível em: $<$ http://pnc.cultura.gov.br/wp-content/uploads/sites/16/2020/04/II-Censo-daInd\%C3\%BAstria-Brasileira-de-Jogos-Digitais_Games_2018.pdf>. Acesso em 18 jun. 2021.

Cavalcante, C. H. L. and Pereira, M. L. A. "Comparativo entre Game Engines como Etapa Inicial para o Desenvolvimento de um Jogo de Educação Financeira". http://ceur-ws.org/Vol-2185/CtrlE_2018 paper_110.pdf Jun, 2018

Campos, L.M.L; Bortoloto, T.M. e Felício, A.K.C. (2002). A produção de jogos didáticos para o ensino de ciências e biologia: uma proposta para favorecer a aprendizagem.http://www.unesp.br/prograd/PDFNE2002/aproducaodejogos.pdf 10 de Junho de 2021.

Carneiro, M. L. F. and Silveira, M. S. (2014) "Objetos de Aprendizagem como elementos facilitadores na Educação a Distância”, https://doi.org/10.1590/01044060.38662, pages 235-260.

CGI.br, (2019) "Comitê Gestor da Internet no Brasil. Pesquisa TIC Domicílios", https://cetic.br/pesquisa/domicilios/indicadores/, 12 de Junho de 2021.

Cordeiro, N. J. N., Costa, M. G.V. and Silva, M. N. (2018) "Educação Financeira no Brasil: uma perspectiva panorâmica", In: Ensino da Matemática em Debate, pages $69-84$.

CNC - Confederação Nacional do Comércio de Bens, Serviços e Turismo. "Pesquisa de Endividamento e Inadimplência do Consumidor (Peic) - fevereiro de 2021” (2021), http://stage.cnc.org.br/editorias/economia/pesquisas/pesquisa-de-endividamento-einadimplencia-do-consumidor-peic-8, 20 de Junho de 2021.

Enger, M, "Game Engines: How do they work?”, (2013), https://www.giantbomb.com/profile/michaelenger/blog/game-engines-how-do-theywork/101529/, 10 de Junho de 2021.

Freitas, S. and Maharg, P., (2011) Digital Games and Learning, Continuum International Publishing Group, London.

Garrett, J. J. (2011) The Elements of User Experience: User-Centered Design for the Web and Beyond. New Riders, Berkeley.

Junior, R. D. C. T., Traspadini, A. T., Sant'Ana, V. A., Nascimento, D. B., Nunes, V. B. 
and Nobre, I. A. M., (2015), "Finance Game: Um Jogo de Apoio à Educação Financeira". Revista Novas Tecnologias na Educação, pages 1-10.

Kliszcz, S., Parreira, F. J. and Silveira, S. R. (2016) "Jogo Educacional Digital para apoio ao aprendizado de Matemática", https://repositorio.ufsm.br/bitstream/handle/1/12840/TCCG SIFW 2015 KLISZCZ _SILVANA.pdf?sequence=1\&isAllowed=y, 27 de Janeiro de 2021 .

Melo, A. (2021) "Sequência de Fibonacci", https://www.estudopratico.com.br/sequencia-de-fibonacci-relacoes-formula-eexemplos/, 05 de Julho de 2021.

Nunes, J. and Infante, M. (1996) "PESQUISA-AÇÃO: Uma Metodologia de Consultoria", http://books.scielo.org/id/dydn3/pdf/amancio-9788575412671-10.pdf, Editora FIOCRUZ, pages 97-114.

Ramos, M. S. F. and Lavor, O. P. (2020) “Análise do Aplicativo Grana como Objeto de Aprendizagem", https://drive.google.com/file/d/1sMIusa0yABQ739uxxvQpN64E2AhXSu5a/view, 20 de Junho de 2021.

Unger, R. and Chandler, C., (2010) Guia Para Projetar UX, Alta Books, Rio de Janeiro.

Vianna, Y., Vianna, M., Medina, B. and Tanaka, S. (2013) Gamification, Inc.: Como reinventar empresas a partir de jogos, MJV Press, Rio de Janeiro, 116p., e-book. 